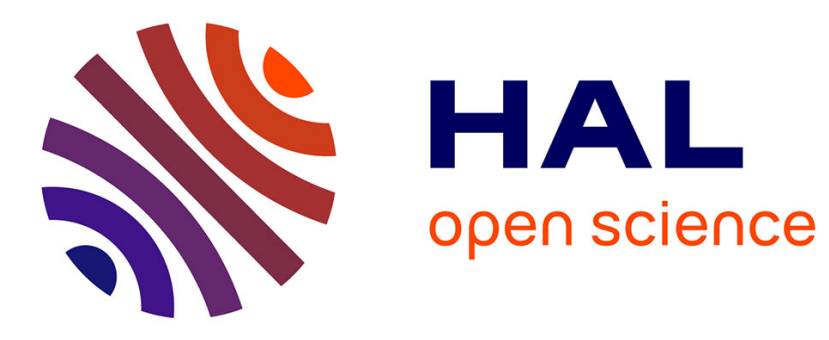

\title{
Thermodynamic stability, structural and electrical characterization of mixed ionic and electronic conductor La2Mo2O8.96
}

Jesús Vega-Castillo, Uday K. Ravella, Gwenaël Corbel, P. Lacorre, Alberto Caneiro

\section{To cite this version:}

Jesús Vega-Castillo, Uday K. Ravella, Gwenaël Corbel, P. Lacorre, Alberto Caneiro. Thermodynamic stability, structural and electrical characterization of mixed ionic and electronic conductor La2Mo2O8.96. Dalton Transactions, 2012, 41 (24), pp.7266. 10.1039/c2dt30261f . hal-02189655

\section{HAL Id: hal-02189655 \\ https://hal.science/hal-02189655}

Submitted on 19 Jul 2019

HAL is a multi-disciplinary open access archive for the deposit and dissemination of scientific research documents, whether they are published or not. The documents may come from teaching and research institutions in France or abroad, or from public or private research centers.
L'archive ouverte pluridisciplinaire HAL, est destinée au dépôt et à la diffusion de documents scientifiques de niveau recherche, publiés ou non, émanant des établissements d'enseignement et de recherche français ou étrangers, des laboratoires publics ou privés. 


\title{
Thermodynamic stability, structural and electrochemical characterization of mixed ionic and electronic conductor $\mathrm{La}_{2} \mathrm{Mo}_{2} \mathrm{O}_{8,96}$
}

\author{
Jesús E. Vega-Castillo, ${ }^{a, b}$ Uday K. Ravella, ${ }^{c}$ Gwenaël Corbel, ${ }^{c}$ Philippe Lacorre ${ }^{c}$ and Alberto Caneiro* $*^{a, b, d}$
}

\begin{abstract}
Thermogravimetric analysis (TGA) technique in controlled oxygen partial pressure $\left(p \mathrm{O}_{2}\right)$ atmospheres has been used to obtain equilibrium oxygen content data as a function of $p \mathrm{O}_{2}$ on the $\mathrm{La}_{2} \mathrm{Mo}_{2} \mathrm{O}_{9-\delta}$ system resulting from the partial reduction of fast oxide-ion conductor $\mathrm{La}_{2} \mathrm{Mo}_{2} \mathrm{O}_{9}$ (LM). Thermodynamic conditions for stabilization of crystalline $\mathrm{La}_{7} \mathrm{Mo}_{7} \mathrm{O}_{30}$ and amorphous $\mathrm{La}_{2} \mathrm{Mo}_{2} \mathrm{O}_{7-y}$ at $718{ }^{\circ} \mathrm{C}$ have been determined and discussed. At $608^{\circ} \mathrm{C}$, the compound reported for the first time $\mathrm{La}_{2} \mathrm{Mo}_{2} \mathrm{O}_{8.96}$ (LM896) has been found. The crystalline form and transition temperature in LM896 have been identified by X-ray diffraction at room temperature (XRD) and at controlled temperature. Conductivity curves obtained by electrochemical impedance spectroscopy (EIS) as a function of temperature for both LM and LM896 have been compared. The results indicate that LM896 is a mixed ionic and electronic conductor (MIEC).
\end{abstract}

\section{Introduction}

Solid oxide fuel cells (SOFC) use three basic components: a dense oxide ion conductor electrolyte, and two porous hybrid (cermet) or mixed ionic and electronic conducting electrodes, a cathode for oxygen reduction and an anode for fuel oxidation. ${ }^{1,2}$ The currently used material as electrolyte in SOFCs is yttria stabilized zirconia (YSZ), which exhibits good ionic conductivity values only above $800{ }^{\circ} \mathrm{C}$. This high temperature makes necessary the use of expensive interconnection materials such as lanthanum chromites. The decrease of operating temperature in SOFCs by at least $200{ }^{\circ} \mathrm{C}$ would lead to make this technology, known as intermediate temperature solid oxide fuel cells (IT-SOFC), economically competitive. $\mathrm{La}_{2} \mathrm{Mo}_{2} \mathrm{O}_{9}$ (LM) is a fast oxide ion conductor discovered in $2000 .{ }^{3}$ Above $\sim 580{ }^{\circ} \mathrm{C}$ this material undergoes a reversible $\alpha$ (monoclinic) to $\beta$ (cubic) phase transition with an abrupt increase of ionic conductivity up to values about one order of magnitude higher than those of YSZ. The main drawback in order to implement LM as an electrolyte for IT-SOFC is its poor stability under reducing atmospheres at temperatures above $600{ }^{\circ} \mathrm{C} .{ }^{4.5}$ The family of oxide ion conductors obtained by cationic substitutions on $\mathrm{LM}, \mathrm{La}_{2}$ ${ }_{-x} \mathrm{~A}_{x} \mathrm{MO}_{2-\gamma} \mathrm{B}_{y} \mathrm{O}_{9-\delta}$, is known as LAMOX ${ }^{6-19}$ The partial substitution of Mo by $\mathrm{W}, \mathrm{La}_{2} \mathrm{Mo}_{2-y} \mathrm{~W}_{y} \mathrm{O}_{9}$, has been reported to

\footnotetext{
${ }^{a}$ Instituto Balseiro, Centro Atómico Bariloche, 8400 San Carlos de Bariloche, Río Negro, Argentina

${ }^{b}$ Consejo Nacional de Investigaciones Cientificas y Técnicas CONICET, Argentina

'LUNAM Université, Université du Maine, CNRS UMR 6283, Institut des Molécules et des Matériaux du Mans, Avenue Olivier Messiaen, 72085 Le Mans Cedex 9, France

Comisión Nacional de Energía Atómica CNEA, Argentina. E-mail: caneiro@cab.cnea.gov.ar
}

improve the stability of LAMOX compounds against reduction. ${ }^{9,17,18}$

The partial reduction of LM can lead to amorphization or to the formation of phases with different crystalline structures and oxygen contents. Different authors have found an amorphous phase after partially reducing LM under diluted hydrogen at temperatures from 600 to $760{ }^{\circ} \mathrm{C}$. $9,18,19$ This amorphous compound presents electronic conductivity and it has been tested as sulfur tolerant anode material for SOFC. ${ }^{24}$ The stabilization of perovskite related $\mathrm{La}_{7} \mathrm{Mo}_{7} \mathrm{O}_{30}$ at temperatures between 700 and $760{ }^{\circ} \mathrm{C}$ in reducing atmosphere has also been observed. ${ }^{18,19}$ In a previous work we have found that at $1000{ }^{\circ} \mathrm{C}$, the reduction of LM results into the apparition of a mixture of two partially reduced molybdate phases, whose compositions depend on the oxygen partial pressure $\left(p \mathrm{O}_{2}\right)$ range. ${ }^{5}$

Some works suggest that LM can keep its crystal structure under certain reductive conditions and even behave as mixed ionic and electronic conductor (MIEC). Georges et al. reported the conservation of LAMOX structure after reducing LM in Ar$(10 \%) \mathrm{H}_{2}$ at $605{ }^{\circ} \mathrm{C}$. ${ }^{21}$ Marrero-López et al. also found by X-ray diffraction (XRD) that LM keeps its structure after annealing in $\mathrm{Ar}-(5 \%) \mathrm{H}_{2}$ at temperatures below $700{ }^{\circ} \mathrm{C}$ for $24 \mathrm{~h} .{ }^{22}$ These results are in apparent contradiction with a more recent work, ${ }^{5}$ in which a continuous reduction of LM ceramic is detected at $608{ }^{\circ} \mathrm{C}$ under $\mathrm{Ar}-(10 \%) \mathrm{H}_{2}$, leading to amorphization. This discrepancy could be attributed to the dependence of the reduction path in LM on the gas flow rate which is relatively high, $6 \mathrm{~L} \mathrm{~h}^{-1}$, in the last cited work. ${ }^{5}$ Indeed, Jacquens et al. performed electrochemical impedance spectroscopy (EIS) measurements on $\mathrm{La}_{2} \mathrm{Mo}_{2-y} \mathrm{~W}_{y} \mathrm{O}_{9}$ annealed in $\mathrm{Ar}-(10 \%) \mathrm{H}_{2}$ flowing at $0.6 \mathrm{~L} \mathrm{~h}^{-1}$ at $608{ }^{\circ} \mathrm{C}$. ${ }^{25}$ After annealing for $24 \mathrm{~h}$ at $608{ }^{\circ} \mathrm{C}$, all cubic W-LAMOX specimens, even the most sensitive member of this series, $\alpha \mathrm{La}_{2} \mathrm{Mo}_{2} \mathrm{O}_{9}$, have kept their initial structure. The increasc in total conductivity measured in dilute hydrogen is ascribed to 
the generation of an electronic contribution arising from the partial reduction of molybdenum. This contribution is more pronounced when the temperature and the tungsten content $y$ are low.

Recently, Goel et al. analysed the increase of electrical conductivity on $\mathrm{La}_{2} \mathrm{Mo}_{2-y} \mathrm{~W}_{y} \mathrm{O}_{9}$ under $\mathrm{Ar}-(10 \%) \mathrm{H}_{2} \cdot{ }^{26}$ They found that the electrical conductivity of these partial reduced samples varies depending on both the porosity of initial ceramics and the W content.

In this work, we aim to analyse the stability limits of $p \mathrm{O}_{2}$ for LM at equilibrium conditions and temperatures close to those meant for IT-SOFC operation. We also study the ranges of stability of the phases present in the $\mathrm{La}_{2} \mathrm{Mo}_{2} \mathrm{O}_{9-\delta}$ system at these temperatures.

\section{Experimental}

\section{Synthesis of LM powders and ceramics}

$\mathrm{La}_{2} \mathrm{Mo}_{2} \mathrm{O}_{9}$ raw powders were prepared by standard solid state reaction. Stoichiometric amounts of $\mathrm{La}_{2} \mathrm{O}_{3}$ and $\mathrm{MoO}_{3}$ were weighed and mixed in an agate mortar. $\mathrm{La}_{2} \mathrm{O}_{3}$ was previously dehydrated and decarbonated at $1000{ }^{\circ} \mathrm{C}$ for $2 \mathrm{~h}$. The mixed oxides were annealed at $500{ }^{\circ} \mathrm{C}$ for $12 \mathrm{~h}$ to prevent Mo sublimation and then fired at $900{ }^{\circ} \mathrm{C}$ for $12 \mathrm{~h}$. Several grindings and heat treatments were necessary to obtain pure LM.

In order to prepare a dense LM pellet, $5 \mathrm{~g}$ of raw powders were ball-milled into an agate jar with 20 agate balls $(10 \mathrm{~mm}$ in diameter) in ethanol for $15 \mathrm{~min}$. Approximately $500 \mathrm{mg}$ of milled powder were shaped into a cylindrical pellet by pressing uniaxially under 1 ton. The green pellet was sintered at $1200{ }^{\circ} \mathrm{C}$ for $2 \mathrm{~h}$. The sintered pellet had $92 \%$ of the theoretical density value with thickness and diameter of 4.53 and $5.30 \mathrm{~mm}$, respectively.

\section{Equilibrium TGA and $p \mathrm{O}_{2}$ control}

Equilibrium measurements at constant temperatures of 718 and $608{ }^{\circ} \mathrm{C}$ in a controlled atmosphere were carried out by using a Cahn 1000 thermobalance coupled to an electrochemical $p \mathrm{O}_{2}$ control system. ${ }^{27}$ Atmospheres with controlled $\mathrm{pO}_{2}$ are set by flowing a carrier gas through an electrochemical oxygen pump and an electrochemical oxygen sensor. The pump enables to modify the $\mathrm{pO}_{2}$ in the gas following Faraday's law while the sensor uses Nernst's law to measure the set $\mathrm{pO}_{2}$ value. The symmetrical thermobalance allows both to detect when the steady state is reached and to measure the oxygen content of the sample.

Ar, $\mathrm{CO}_{2}$ and $\mathrm{Ar}-\mathrm{H}_{2}$ were used as carrier gases to supply the oxygen pump. The highest $p \mathrm{O}_{2}$ corresponded to that obtained in $\operatorname{Ar}\left(p \mathrm{O}_{2}=3 \times 10^{-6} \mathrm{~atm}\right.$, value due to residual oxygen in commercial Ar 5.0). Intermediate $\mathrm{pO}_{2}$ range was set by electrochemical reduction of $\mathrm{CO}_{2}$ giving $\mathrm{CO}-\mathrm{CO}_{2}$ atmospheres. The low $p \mathrm{O}_{2}$ implemented range was obtained by oxidizing $\mathrm{Ar}-\mathrm{H}_{2}$ and generating $\mathrm{Ar}-\mathrm{H}_{2}-\mathrm{H}_{2} \mathrm{O}$. The gas flow rate for all equilibrium measurements was set to $6 \mathrm{~L} \mathrm{~h}^{-1}$. Each equilibrium point was recorded after a constant TGA signal (mass variation lower than $1 \mu \mathrm{g}$ ) for at least $5 \mathrm{~h}$.

Approximately $500 \mathrm{mg}$ of LM raw powder were placed into an alumina crucible in the thermobalance. The sample was heated up in flowing Ar; once at the working temperature, the equilibrium was reached. The mass value obtained under $\mathrm{Ar}$ with $\mathrm{pO}_{2}=3 \times 10^{-6}$ atm was used as reference for stoichiometric $\mathrm{La}_{2} \mathrm{Mo}_{2} \mathrm{O}_{9}(\delta=0)$. This reference was verified under pure oxygen $\left(p \mathrm{O}_{2}=1 \mathrm{~atm}\right)$. The $p \mathrm{O}_{2}$ value was then decreased by switching the atmosphere and the annealing maintained until a new equilibrium was detected. This procedure was repeated as the $\mathrm{O}_{2}$ was gradually decreased down to the minimum adjustable value with dry $\mathrm{Ar}-\mathrm{H}_{2}$.

\section{Structural characterization}

The phase purity of powder and pellet samples after their annealing in the thermobalance and quenching under controlled oxygen partial pressure was checked by XRD at room temperature. Diffractograms were collected on a Philips PW1700 diffractometer with $\mathrm{Cu}\left(\mathrm{K}_{\alpha 1}+\mathrm{K}_{\alpha 2}\right)$ radiation and a graphite monochromator and a PANalytical q/q Bragg-Brentano X'pert MPD PRO diffractometer $\mathrm{Cu}\left(\mathrm{K}_{\alpha 1}+\mathrm{K}_{\alpha 2}\right)$ equipped with the $\mathrm{X}$ 'Celerator multi-elements detector.

In situ XRD measurements under controlled oxygen partial pressure were carried out at different annealing temperatures by using an Anton-Paar HTK10 camera coupled to the electrochemical $\mathrm{pO}_{2}$ control system described in the previous subsection. In this manner it is possible to record XRD patterns at high temperature under controlled $\mathrm{pO}_{2}$ atmosphere.

\section{Electrical characterization}

LM and LM896 were characterized by EIS in different atmospheres using a symmetrical electrochemical cell. Pt electrodes were sputtered onto both flat sides of cylindrical LM pellet. The sample was placed in an alumina cell inside a cylindrical furnace, with Pt mesh as current collectors. This setup can also be connected to the electrochemical $\mathrm{pO}_{2}$ control system.

EIS spectra were collected from 250 up to $608{ }^{\circ} \mathrm{C}$ by means of a frequency response analyser (FRA) coupled to an Autolab potentiostat, within a frequency range of $1 \mathrm{MHz}$ to $0.1 \mathrm{~Hz}$ and voltage amplitude of $50 \mathrm{mV}$. The measured spectra were analyzed using Zview software. ${ }^{28}$ A $\mathrm{R} \| \mathrm{C}$ pe circuit was used to model the high frequency contribution (bulk) for spectra recorded in air and Ar (stoichiometric LM). For spectra recorded on partially reduced $\mathrm{La}_{2} \mathrm{Mo}_{2} \mathrm{O}_{9-\delta}, 0<\delta \leq 0.04$, in $\mathrm{Ar}-\mathrm{H}_{2}-\mathrm{H}_{2} \mathrm{O}$ atmosphere, the high frequency contribution was adjusted with only one resistance element. The total conductivity values $\sigma$ for $\mathrm{LM}$ and $\mathrm{La}_{2} \mathrm{Mo}_{2} \mathrm{O}_{9-\delta}$ were calculated from the resistance values $R$ in the respective equivalent circuits, the measured thickness $L$ and surface area $A$ of the pellet as follows: $\sigma=L(A R)^{-1}$. For all spectra, the Pt electrode contribution was modelled with a short Warburg element in series with the high frequency circuit.

\section{Results and discussion}

\section{Reduction of $\mathrm{La}_{2} \mathrm{Mo}_{2} \mathrm{O}_{9}$ at $718{ }^{\circ} \mathrm{C}$ : stability of $\mathrm{La}_{7} \mathrm{Mo}_{7} \mathrm{O}_{30}$ and amorphous $\mathrm{La}_{2} \mathrm{Mo}_{2} \mathrm{O}_{7-y}$}

The oxygen content $9-\delta$ in $\mathrm{La}_{2} \mathrm{Mo}_{2} \mathrm{O}_{9-\delta}$ as a function of decreasing $\mathrm{pO}_{2}$ at $718{ }^{\circ} \mathrm{C}$ is shown in Fig. 1. As explained in Experimental section, the first measurement was performed in $\mathrm{Ar}$ (closed square) and afterwards the $\mathrm{pO}_{2}$ was gradually 


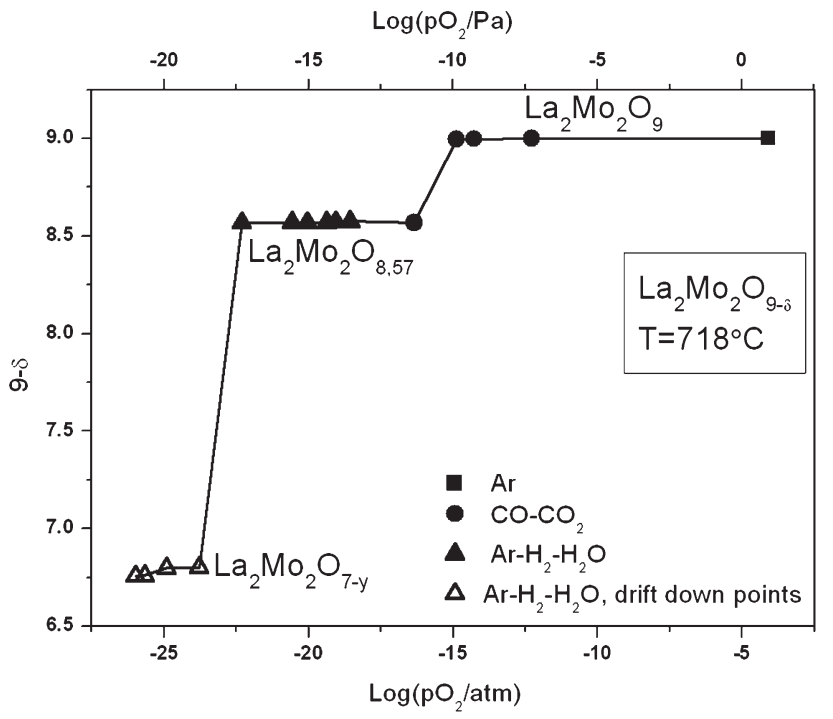

Fig. 1 Oxygen content as a function of $p \mathrm{O}_{2}$ in $\mathrm{La}_{2} \mathrm{Mo}_{2} \mathrm{O}_{9-\delta}$ at $718^{\circ} \mathrm{C}$.

decreased. The oxygen content remains as 9 as long as the $p \mathrm{O}_{2}$ is above $10^{-15} \mathrm{~atm}$. It delineates the thermodynamic stability range for stoichiometric $\mathrm{LM}$ at $718{ }^{\circ} \mathrm{C}$. As $p \mathrm{O}_{2}$ is slightly decreased down to $10^{-16} \mathrm{~atm}$, an abrupt oxygen loss of $\delta=0.43$ is observed after five days. A further decrease of the oxygen partial pressure down to $10^{-22}$ atm does not induce any change in the oxygen content of the sample. Therefore, the $9-\delta=8.57$ stoichiometry is thermodynamically stable at $718{ }^{\circ} \mathrm{C}$ within the range $10^{-22}<p \mathrm{O}_{2}<10^{-15} \mathrm{~atm}$.

When decreasing $p \mathrm{O}_{2}$ below $10^{-22}$ atm a slow reduction takes place again and in this case a steady state, indicating thermodynamic equilibrium, is never properly reached. Instead, a pseudoplateau with a drift down is detected in the TGA signal $v s$. time at $9-\delta$ values lower than 7 (open triangles in Fig. 1). The presence of a linear drift that increases when $p \mathrm{O}_{2}$ decreases suggests that the compound $\mathrm{La}_{2} \mathrm{Mo}_{2} \mathrm{O}_{7-y}$ has no fixed oxygen stoichiometry and it losses oxygen continuously with kinetics depending on the $p \mathrm{O}_{2}$.

In order to determine the nature of phases (or mixture of phases) corresponding to the found stoichiometries $9-\delta=8.57$ and $7-y$, two batches of LM raw powders were annealed at $718^{\circ} \mathrm{C}$ in the TGA equipment in atmospheres with $p \mathrm{O}_{2}$ values of $10^{-20}$ and $10^{-24} \mathrm{~atm}$, respectively. Once the oxygen content of each batch reached constant 8.57 and $7-y$ (with a drift as described in previous paragraph), respectively, the samples were quenched down to room temperature while maintaining the atmosphere. XRD patterns of quenched powders compared to those of initial LM are shown in Fig. 2. $\mathrm{La}_{2} \mathrm{Mo}_{2} \mathrm{O}_{8.57}$ has been confirmed as $\mathrm{La}_{7} \mathrm{Mo}_{7} \mathrm{O}_{30}$ perovskite related phase, while $\mathrm{La}_{2} \mathrm{Mo}_{2} \mathrm{O}_{7-y}$ is amorphous.

\section{Discussion on equilibrium $p \mathrm{O}_{2}$ data at $718{ }^{\circ} \mathrm{C}$}

Several authors have observed the formation of $\mathrm{La}_{7} \mathrm{Mo}_{7} \mathrm{O}_{30}$ as intermediate product during partial reduction of LM in different reducing atmospheres. ${ }^{18,19}$ Indeed, Goutenoire was able to synthesize a large amount of $\mathrm{La}_{7} \mathrm{Mo}_{7} \mathrm{O}_{30}$ in order to determine its crystal structure from neutron diffraction analysis by reducing LM in $\mathrm{N}_{2}-(6 \%) \mathrm{H}_{2}$ at $760{ }^{\circ} \mathrm{C}^{23}$ Nevertheless, they clarify that if

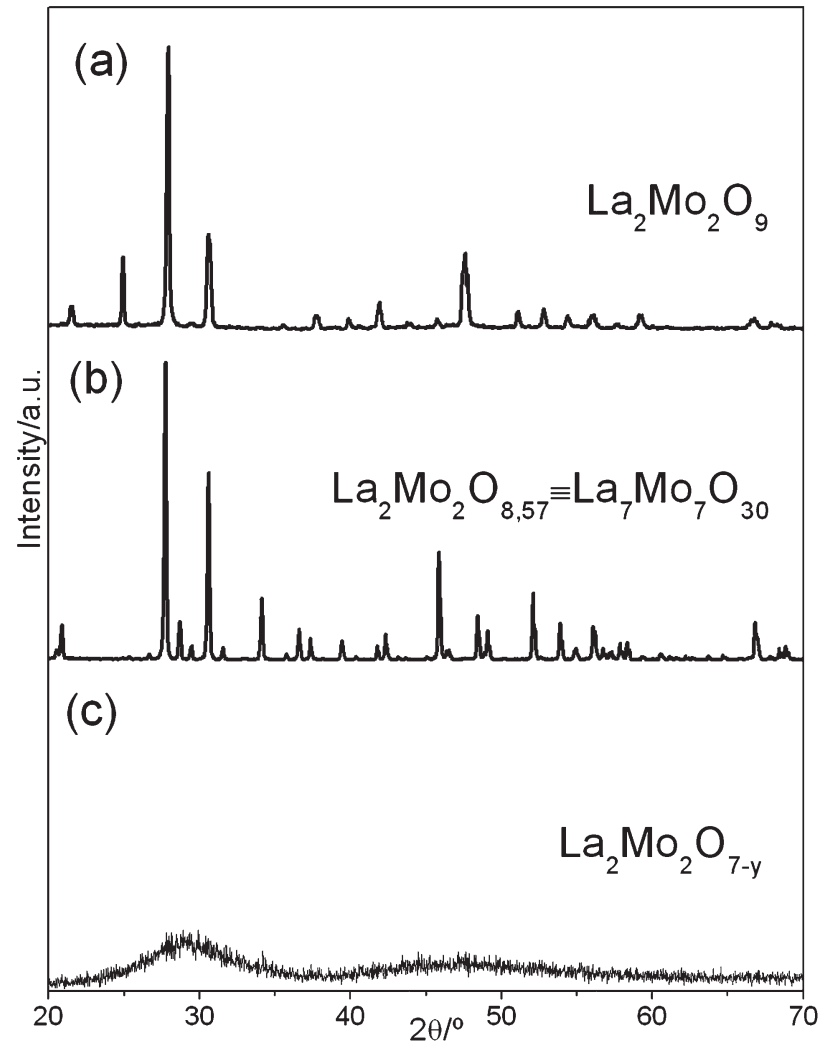

Fig. 2 XRD patterns of $\mathrm{La}_{2} \mathrm{Mo}_{2} \mathrm{O}_{9-\delta}$ stabilized at $718{ }^{\circ} \mathrm{C}$ in different atmospheres and quenched down to room temperature with $9-\delta$ values of (a) 9 , (b) 8.57 and (c) $7-y$.

the atmosphere and temperature are maintained the reduction continues until amorphization of the compound. In other words, $\mathrm{La}_{7} \mathrm{Mo}_{7} \mathrm{O}_{30}$ is a meta-stable phase at $760{ }^{\circ} \mathrm{C}$ in $\mathrm{N}_{2}-(6 \%) \mathrm{H}_{2}$ atmosphere. We think that the reproducible transient stabilization of $\mathrm{La}_{7} \mathrm{Mo}_{7} \mathrm{O}_{30}$ from reduction of $\mathrm{LM}$ in $\mathrm{N}_{2}-(6 \%) \mathrm{H}_{2}$ at $760{ }^{\circ} \mathrm{C}$ is due to kinetic effects related to the gas flow rate (not specified in the cited work) and also to the used gas mixture. In fact, we have been able to reproduce Goutenoire's experiment under the same conditions obtaining the TGA plateau of $\mathrm{La}_{7} \mathrm{Mo}_{7} \mathrm{O}_{30}$. Nevertheless when we have repeated the experiment under the same conditions but replacing $\mathrm{N}_{2}-(6 \%) \mathrm{H}_{2}$ by $\mathrm{Ar}-(5 \%) \mathrm{H}_{2}$, this plateau was not reached and the reduction continued directly until the amorphization of the sample.

In our equilibrium experiments, $\mathrm{La}_{7} \mathrm{Mo}_{7} \mathrm{O}_{30}$ remained stable at $718{ }^{\circ} \mathrm{C}$ in atmospheres with $p \mathrm{O}_{2}$ values within the range $10^{-22}<p \mathrm{O}_{2}<10^{-15} \mathrm{~atm}$ (we have kept the treatment for even several days with no change observed in the mass signal). This indicates that $\mathrm{La}_{7} \mathrm{Mo}_{7} \mathrm{O}_{30}$ is thermodynamically stable in the described conditions. The use of high gas flow rates in our equilibrium experiments enhances the kinetics of the reduction processes and avoids confusing meta-stable states with thermodynamically stable ones.

Regarding the observed amorphous compound (see Fig. 2(c)), in our previous work we had referred it to $\mathrm{La}_{2} \mathrm{Mo}_{2} \mathrm{O}_{6.88}{ }^{5}$ Nevertheless, subsequent experiments including the one here reported indicate an oxygen non-stoichiometric range for this amorphous phase, leading us to revise that chemical formula. We have opted to use $\mathrm{La}_{2} \mathrm{Mo}_{2} \mathrm{O}_{7-y}$ as approximated chemical formula for this 
amorphous material. We deduce from our measurements that $y$ in $\mathrm{La}_{2} \mathrm{Mo}_{2} \mathrm{O}_{7-y}$ should be in the $0<y<1$ range.

\section{Reduction of $\mathrm{La}_{2} \mathrm{Mo}_{2} \mathrm{O}_{9}$ at $608{ }^{\circ} \mathrm{C}$ : stability and characterization of $\mathrm{La}_{2} \mathrm{Mo}_{2} \mathrm{O}_{8.96}$}

In order to determine whether the $\mathrm{La}_{7} \mathrm{Mo}_{7} \mathrm{O}_{30}$ phase exists at a lower temperature, an equilibrium experiment in controlled atmosphere at $608{ }^{\circ} \mathrm{C}$ was performed.

Fig. 3 shows the oxygen content $9-\delta$ in $\mathrm{La}_{2} \mathrm{Mo}_{2} \mathrm{O}_{9-\delta}$ as a function of $p \mathrm{O}_{2}$ at $608{ }^{\circ} \mathrm{C}$. At this temperature the $p \mathrm{O}_{2}$ stability limit for $\mathrm{La}_{2} \mathrm{Mo}_{2} \mathrm{O}_{9}$ is $10^{-22}$ atm. Below this value the sample undergoes a slight reduction down to an oxygen content of 8.96. The stoichiometry 8.96 remains unchanged within the range $10^{-25}<p \mathrm{O}_{2}<10^{-23} \mathrm{~atm}$. Below $10^{-25}$ atm the sample reduces slowly down to amorphous $\mathrm{La}_{2} \mathrm{Mo}_{2} \mathrm{O}_{7-y}$

The reproducibility of $\mathrm{La}_{2} \mathrm{Mo}_{2} \mathrm{O}_{8.96}$ (LM896) was checked by several oxidizing-reducing cycles between $9-\delta=9$ and 8.96 . LM896 can also be recovered by oxidation from amorphous $\mathrm{La}_{2} \mathrm{Mo}_{2} \mathrm{O}_{7-y}$. The reproducibility of LM896 upon reduction-oxidation confirms that the found $\mathrm{pO}_{2}$ values corresponding to LM896 represent true thermodynamic equilibrium states. LM896 powders for XRD characterization were obtained from annealing $\mathrm{LM}$ at $608{ }^{\circ} \mathrm{C}$ in an atmosphere with a $p \mathrm{O}_{2}$ of $10^{-24}$ atm in the TGA setup until total stabilization at $9-\delta=8.96$ was reached. The reduction of $500 \mathrm{mg}$ from LM to LM896 took $200 \mathrm{~min}$. The homogeneously light gray LM896 powders were then quenched down to room temperature and analyzed by XRD; the results are shown in Fig. 4. The X-ray diffractograms of LM and LM896 are identical. Both pseudo-cubic (2 3 1) reflections (at $2 \theta$ around $47.5^{\circ}$ ) are compared in the inset, the notorious peak splitting characteristic of $\alpha \mathrm{La}_{2} \mathrm{Mo}_{2} \mathrm{O}_{9}$ indicates that LM896 has also a monoclinic symmetry at room temperature. XRD patterns of LM and quenched LM896 were fitted using constant scale factors (Lebail) within FULLPROF software, ${ }^{29}$ in monoclinic $P 2_{1}$ space group ignoring weak $(2 \times 3 \times$ 4) superstructure peaks. ${ }^{30}$ The obtained cell volumes were 366.05(1) $\AA^{3}$ for LM and 365.71(1) $\AA^{3}$ for LM896 showing a slight contraction after reduction. The respective cell parameters were $a=7.1414(1) \AA, b=7.1538(1) \AA, c=7.1653(1) \AA$ and $\beta=$ $89.530(1)^{\circ}$ for LM and $a=7.1411(1) \AA, b=7.1520(1) \AA, c=$ 7.1608(1) $\AA$ and $\beta=89.584(1)^{\circ}$ for LM896.

The structure of $\alpha \mathrm{La}_{2} \mathrm{Mo}_{2} \mathrm{O}_{9}$ has been described as one of the most complex structures reported to date. ${ }^{31}$ The monoclinic cell has a number of formula units $Z=48$, so, the chemical formula contained in the asymmetric cell can be written as $\mathrm{La}_{96} \mathrm{Mo}_{96} \mathrm{O}_{432}$. In the case of $\alpha \mathrm{La}_{2} \mathrm{Mo}_{2} \mathrm{O}_{8.96}, 48$ formula units would equal to $\mathrm{La}_{96} \mathrm{Mo}_{96} \mathrm{O}_{430}$. This corresponds to a loss of two $\mathrm{O}$ atoms per monoclinic cell, which is consistent with maintaining the monoclinic $P 2_{1}$ symmetry of $\alpha \mathrm{La}_{2} \mathrm{Mo}_{2} \mathrm{O}_{8.96}$, with departure from $\mathrm{La}_{2} \mathrm{Mo}_{2} \mathrm{O}_{9}$ of 2 equivalent $\mathrm{O}$ atoms related by the $2_{1}$ screw axis.

\section{HT-XRD on LM896 powders}

In order to determine if LM896 undergoes a monoclinic-cubic transition, approximately $20 \mathrm{mg}$ of LM raw powders were heated up to $608{ }^{\circ} \mathrm{C}$ inside the HT-XRD setup in He atmosphere. At this temperature, the atmosphere was switched to $\mathrm{He}-\mathrm{Ar}-\mathrm{H}_{2}-$ $\mathrm{H}_{2} \mathrm{O}$ with a set $p \mathrm{O}_{2}$ of $10^{-24}$ atm. After 200 min of annealing,

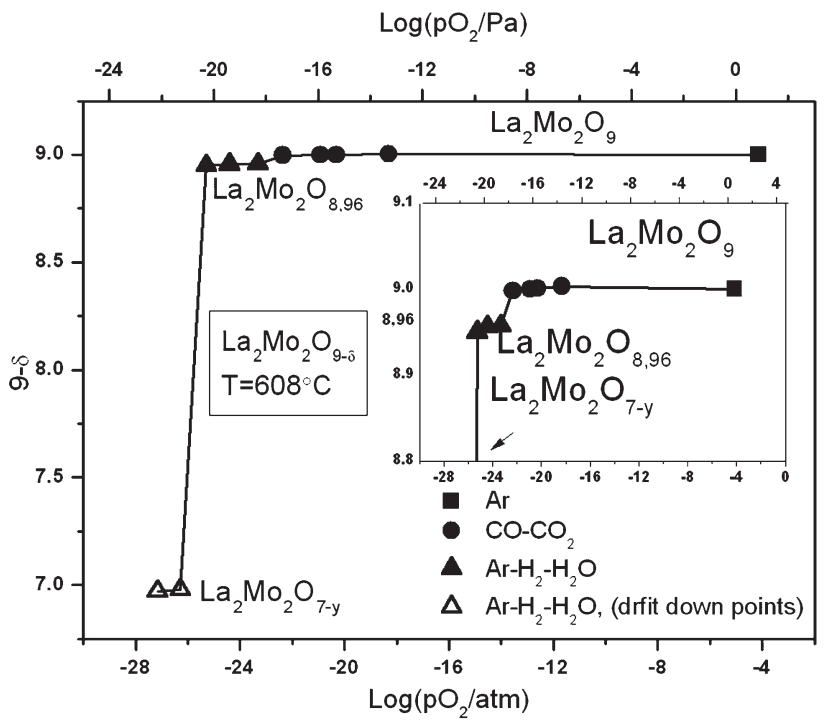

Fig. 3 Oxygen content as a function of $p \mathrm{O}_{2}$ in $\mathrm{La}_{2} \mathrm{Mo}_{2} \mathrm{O}_{9-\delta}$ at $608^{\circ} \mathrm{C}$.

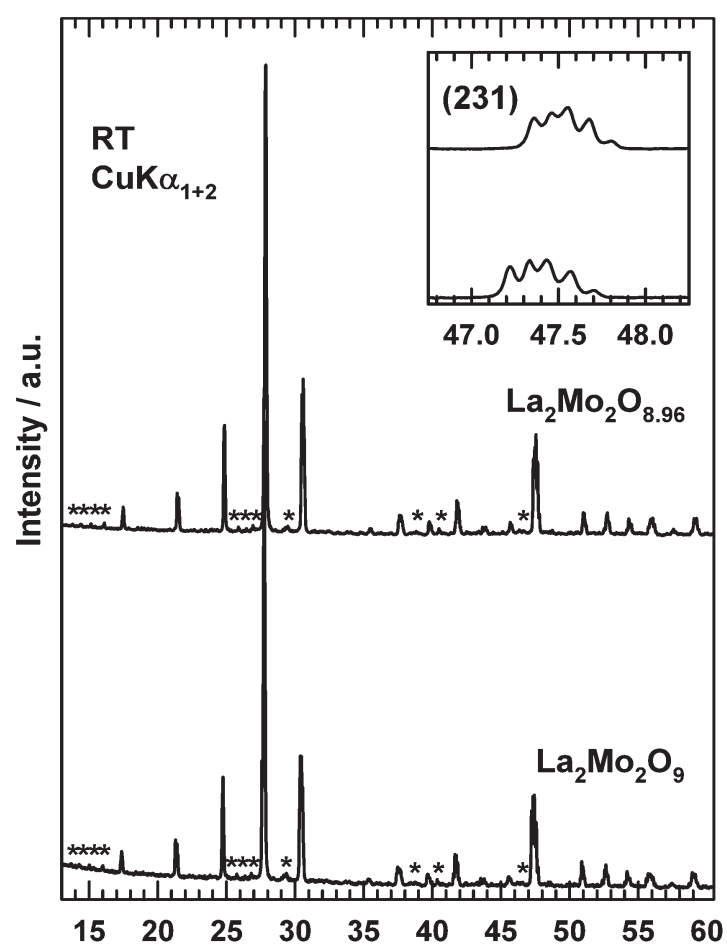

Fig. 4 Room-temperature X-ray diffraction patterns of raw $\mathrm{La}_{2} \mathrm{Mo}_{2} \mathrm{O}_{9}$ and quenched $\mathrm{La}_{2} \mathrm{Mo}_{2} \mathrm{O}_{8.96}$ powder samples showing the superstructure peaks $(*)$ and the splitting of the cubic (2 31 ) peak (inset), both characteristic of the monoclinic low temperature $\alpha$ form.

the stabilization of $\mathrm{La}_{2} \mathrm{Mo}_{2} \mathrm{O}_{8.96}$ was assumed, based on the kinetics observed in TGA experiments described in previous subsection. Fig. 5 shows the XRD pattern collected at $608{ }^{\circ} \mathrm{C}$ on the LM896 phase (black line) in the vicinity of the most intense (1 220$)$ peak of a beta-LM-type phase (gray line). A slight shift to higher $2 \theta$ values is visible indicating once again a contraction of the unit cell after reduction from LM to LM896. At $608{ }^{\circ} \mathrm{C}$ LM896 is in cubic symmetry (isostructural to $\mathrm{\beta La}_{2} \mathrm{Mo}_{2} \mathrm{O}_{9}$ ) as indicated by the absence of splitting in $\left(\begin{array}{lll}2 & 3 & 1\end{array}\right)$ reflection shown 


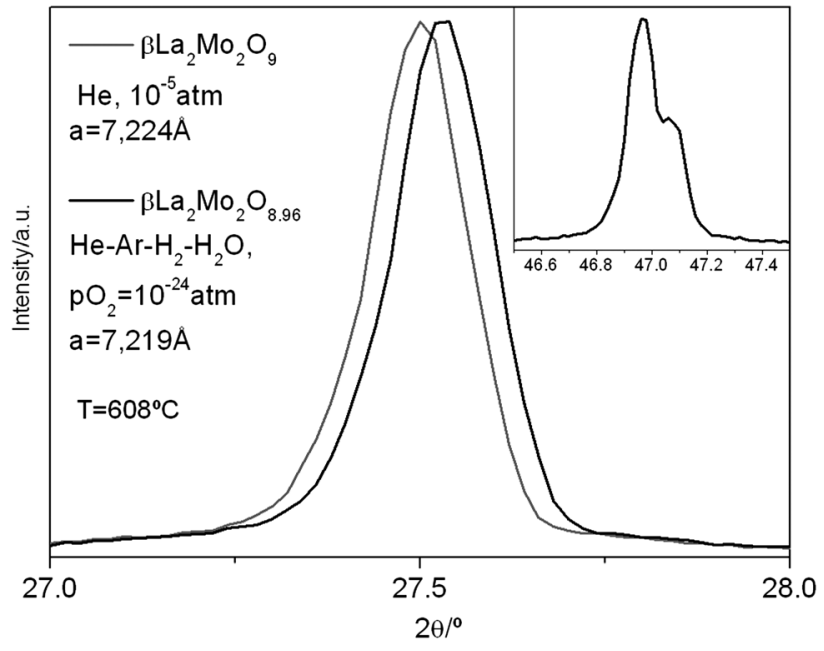

Fig. 5 Comparison of XRD patterns at $608{ }^{\circ} \mathrm{C}$ of cubic LM and

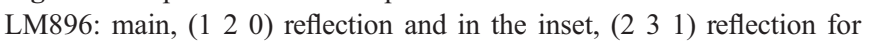
LM896 at $608{ }^{\circ} \mathrm{C}$.

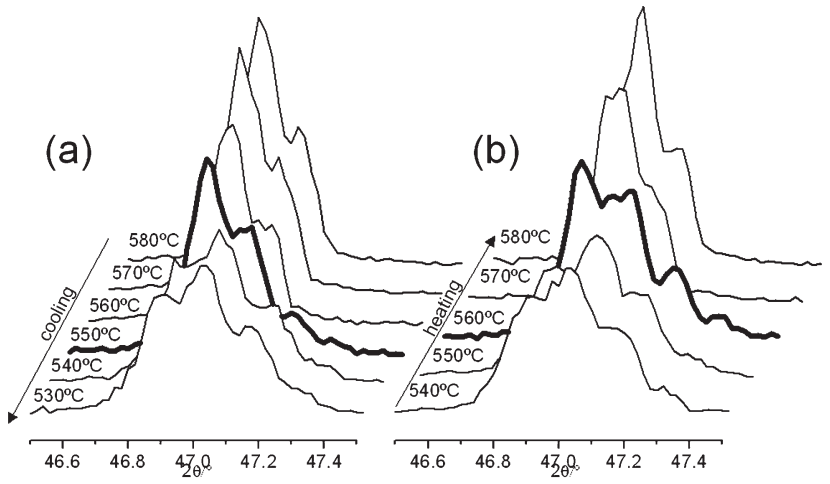

Fig. 6 Cubic or pseudo-cubic (2 3 1) XRD reflection for LM896 at different temperatures: (a) while cooling down, (b) while heating.

in the inset of Fig. 5 (double reflection due to $\mathrm{CuK}_{\alpha 1}$ and $\mathrm{CuK}_{\alpha 2}$ radiations). The cubic cell parameters obtained from Rietveld refinement in $P 2{ }_{1} 3$ space group are 7.2240(1) $\AA$ for LM and 7.2195(1) \& for LM896.

Aiming at determining the $\alpha \leftrightarrow \beta$ transition temperature for LM896, the (2 3 1) reflection was monitored at different temperatures by HT-XRD while cooling down from $608{ }^{\circ} \mathrm{C}$. Fig. 6 shows how the monoclinic distortion shows up at $550{ }^{\circ} \mathrm{C}$ upon cooling, while on heating, both symmetries coexist at $560{ }^{\circ} \mathrm{C}$. These values are identical to those observed for LM powders in air upon both cooling and heating in the same HTXRD setup.

\section{Electrical characterization of $\mathrm{La}_{2} \mathrm{Mo}_{2} \mathrm{O}_{8.96}$}

As other authors have observed, the partial reduction of Mo in $\mathrm{La}_{2} \mathrm{Mo}_{2} \mathrm{O}_{9-\delta}$ leads to an increase of electrical conductivity. ${ }^{20,25,26}$ This behaviour would be expected for LM896 compound. Arrhenius plots of measured conductivity values for both LM (in air) and LM896 (in $\mathrm{Ar}-\mathrm{H}_{2}-\mathrm{H}_{2} \mathrm{O}$ ) are shown in Fig. 7. The curve corresponding to LM (squares) was recorded while heating up to $608{ }^{\circ} \mathrm{C}$ in air. At this point the atmosphere was switched by $\mathrm{Ar}-\mathrm{H}_{2}-\mathrm{H}_{2} \mathrm{O}$ with a controlled $p \mathrm{O}_{2}$ of $10^{-24} \mathrm{~atm}$. The total resistance of the sample was then monitored as a

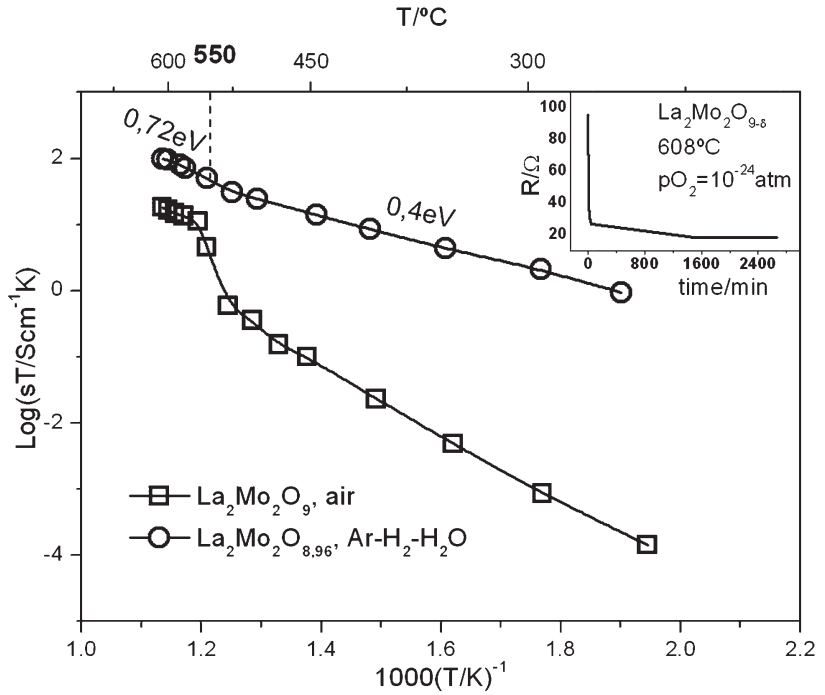

Fig. 7 Conductivity as a function of temperature for LM in air and LM896 in $\mathrm{Ar}-\mathrm{H}_{2}-\mathrm{H}_{2} \mathrm{O}$.

function of time (see inset in Fig. 7) and once a plateau was obtained, the stabilization of LM896 was assumed, after $40 \mathrm{~h}$. The Arrhenius curve of LM896 shows a significant increase of conductivity values compared to those of LM, for instance at $\sim 500{ }^{\circ} \mathrm{C}$ the difference is about two orders of magnitude. The curve presents two visible linear zones with different slopes with a break at around $550{ }^{\circ} \mathrm{C}$. From adjusting the linear zones with Arrhenius's law, the calculated activation energies are 0.4 and $0.72 \mathrm{eV}$ for the low and high temperature zones, respectively. Keeping in mind that $550{ }^{\circ} \mathrm{C}$ is the measured $\beta \rightarrow \alpha$ transition temperature for LM896 at cooling, the increase of activation energy can be related to the increase of ionic conductivity associated to this transition. The implemented technique does not allow to discriminate between electronic and ionic conductivity components. Nevertheless, the low activation energies for LM896 suggest predominant electronic conductivity.

\section{Discussion on $\mathrm{La}_{2} \mathrm{Mo}_{2} \mathrm{O}_{8.96}$}

Some authors have suggested that LM exhibits both ionic and electronic conductivities while being partially reduced at temperatures close to $600{ }^{\circ} \mathrm{C} .{ }^{22,25}$ In fact, Jacquens et al. reduced a LM pellet in $\operatorname{Ar}-(10 \%) \mathrm{H}_{2}$ at $608{ }^{\circ} \mathrm{C}$ while monitoring its conductivity by EIS. Once they found stabilization of resistivity values, they characterized the conductivity of the reduced sample as a function of temperature while cooling down in the same atmosphere. ${ }^{25}$ The results obtained by Jacquens et al. are identical to those reported in this work on $\mathrm{La}_{2} \mathrm{Mo}_{2} \mathrm{O}_{8.96}$ electrical characterization. In the cited work, after EIS experiments, XRD identification showed the conservation of LAMOX structure so the authors concluded that LM can withstand partial reduction without decomposing.

We suspect that the results of Jacquens et al. correspond to MIEC $\mathrm{La}_{2} \mathrm{Mo}_{2} \mathrm{O}_{8.96}$ and they were able to stabilize this compound in dry $\mathrm{Ar}-(10 \%) \mathrm{H}_{2}$. This is in apparent contradiction with our equilibrium results, in which while decreasing the $p \mathrm{O}_{2}$ down to $20^{-26} \mathrm{~atm}$, the compound amorphisizes. Theoretically, the oxygen activity in pure dry $\mathrm{Ar}-\mathrm{H}_{2}$ should tend to zero $\left(\log p \mathrm{O}_{2}\right.$ 
$\rightarrow-\infty)$. Nevertheless, in the practice, there is always residual oxygen in high purity gas mixtures and there are leakages in any gas circuit. The effect of incoming oxygen through leakages is more important when the flow rate of the gas source is low since the total flux is the arithmetical addition of all individual gas inputs. Jacquens et al. used a very low flow rate $\left(0.6 \mathrm{~L} \mathrm{~h}^{-1}\right)$ of dry $\mathrm{Ar}-(10 \%) \mathrm{H}_{2}$ so only a small amount of incoming air could have been enough to oxidize a part of $\mathrm{H}_{2}$ setting an $\mathrm{Ar}-\mathrm{H}_{2}-\mathrm{H}_{2} \mathrm{O}$ atmosphere. One of the aims of using high gas flow rate $(6 \mathrm{~L}$ $\mathrm{h}^{-1}$ ) in our experiments is to minimize the effect of the leakages in controlled atmospheres. Another one is to minimize oxygen pressure gradient around the sample by flushing it out.

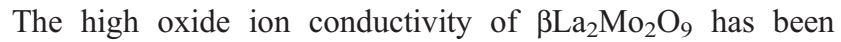
attributed to its crystalline structure and explained with a lonepair substitution concept. ${ }^{32}$ Since the cationic framework of the LAMOX structure is seemingly preserved after reduction, it suggests that oxide ions remain mobile in $\mathrm{La}_{2} \mathrm{Mo}_{2} \mathrm{O}_{8.96}$. On the other hand, the EIS measurements show considerably higher total conductivity values with low activation energies for LM896 compared with those of LM at temperatures below $608{ }^{\circ} \mathrm{C}$. These facts lead us to conclude that the difference in conductivity values between LM and LM896 is due to the appearance of significant electronic conductivity in the latter compound. LM896 is an MIEC stable in reducing atmospheres. Thermal and chemical compatibilities of LM896 with LAMOX based electrolyte materials are presumed, with this novel MIEC being part of the LAMOX family as well.

The compensation of charges for $\mathrm{La}_{2} \mathrm{Mo}_{2} \mathrm{O}_{8.96}$, assuming that the valence state for $\mathrm{La}$ and $\mathrm{O}$ are $3+$ and 2- respectively, yields a total valence state of +5.96 for Mo. The reduction of $\mathrm{Mo}^{6+}$ to a $\mathrm{Mo}^{6+} /(4 \%) \mathrm{Mo}^{5+}$ combination is therefore compensated by the generation of $\mathrm{O}$ vacancies. The reduction to LM896 takes place at $608{ }^{\circ} \mathrm{C}$ in cubic beta form; this structure has three oxygen sites and two of those, $\mathrm{O} 2$ and $\mathrm{O} 3$, are partially occupied. It is logical to suppose that oxygen leaves from $\mathrm{O} 2$ and/or $\mathrm{O} 3$ sites. In the alpha form there are 216 oxygen sites and the vacancies might have a statistical distribution in several sites. Nevertheless, the strict plateau reached at $9-\delta=8.96$ leads us to think that the vacancies should correspond to a full loss at one monoclinic site. Unfortunately, the information available from the present study is not enough to clarify the oxygen vacancies distribution in LM896, neither in alpha or beta symmetry.

The decrease of the unit cell volume indicates that the slight decrease in oxygen stoichiometry involves a larger reduction in volume than the expansion arising from the increase in ionic radius as the valence state of molybdenum is lowered $(0.455 \mathrm{~A}$ for $\mathrm{Mo}^{6+}$ and $0.497 \mathrm{~A}$ for $\mathrm{Mo}^{5+}$ in 4.5 coordination). Note that in $\beta$-LM, taking into account the partial occupancy of $\mathrm{O} 2$ and $\mathrm{O} 3$ sites, the average number of oxygen atoms surrounding Mo is 4.5.

\section{Conclusions}

The thermodynamic $\mathrm{pO}_{2}$ limits for $\mathrm{LM}$ at 718 and $608^{\circ} \mathrm{C}$ were determined as $10^{-15}$ and $10^{-22}$ atm, respectively. The stability range for perovskite related compound $\mathrm{La}_{7} \mathrm{Mo}_{7} \mathrm{O}_{30}$ at $718{ }^{\circ} \mathrm{C}$ was found between $10^{-15}$ and $10^{-22}$ atm of $\mathrm{pO}_{2}$. The novel compound $\mathrm{La}_{2} \mathrm{Mo}_{2} \mathrm{O}_{8.96}$ was found at $608{ }^{\circ} \mathrm{C}$ within the range of $10^{-23}<p \mathrm{O}_{2}<10^{-25}$ atm. This material is isostructural to $\alpha$ (monoclinic) $\mathrm{La}_{2} \mathrm{Mo}_{2} \mathrm{O}_{9}$ below $560{ }^{\circ} \mathrm{C}$ and undergoes a transition to a $\beta$ (cubic) LAMOX structure above this temperature. LM896 is a mixed conductor that exhibits an important electronic conductivity component added to the ionic conductivity values of LM oxide conductor.

\section{Acknowledgements}

This work was financially supported by CNEA (Comisión Nacional de Energía Atómica), CONICET (Consejo Nacional de Investigaciones Científicas y Técnicas), UNCuyo (Universidad Nacional de Cuyo) and ECOS-SUD program, project A07E03.

\section{References}

1 A. Lashtabeg and S. J. Skinner, J. Mater. Chem., 2006, 16, 3161.

2 O. Yamamoto, Electrochim. Acta, 2000, 45, 2423-2435.

3 P. Lacorre, F. Goutenoire, O. Bohnke, R. Retoux and Y. Laligant, Nature, 2000, 404, 856-8.

4 D. Marrero-López, J. C. Ruiz-Morales, D. Pérez-Coll, P. Núñez, J. C. C. Abrantes and J. R. Frade, J. Solid State Electrochem., 2004, 8, 638-643.

5 J. Vega-Castillo, L. Mogni, G. Corbel, P. Lacorre and A. Caneiro, Int. J. Hydrogen Energy, 2010, 35, 5890-5894.

6 C. Tealdi, G. Chiodelli, L. Malavasi and G. Flor, J. Mater. Chem., 2004, 14, 3553

7 X. Wang, Z. Cheng and Q. Fang, Solid State Ionics, 2005, 176, 761-765.

8 D. Marrero-López, D. Perez-Coll, J. C. Ruiz-Morales, J. CanalesVázquez, M. C. Martín-Sedeno and P. Nunez, Electrochim. Acta, 2007, 52, 5219.

9 X. P. Wang, Q. F. Fang, Z. S. Li, G. G. Zhang and Z. G. Yi, Appl. Phys. Lett., 2002, 81, 3434.

10 A. Subramania, T. Saradha and S. Muzhumathi, J. Power Sources, 2007, $167,319$.

11 S. Georges, F. Goutenoire, F. Altorfer, D. Sheptyakov, F. Fauth, E. Suard and P. Lacorre, Solid State Ionics, 2003, 161, 231.

12 D. Marrero-López, J. Canales-Vázquez, W. Zhou, J. T. S. Irvine and P. Núñez, J. Solid State Chem., 2006, 179, 278-288.

13 G. Corbel, P. Durand and P. Lacorre, J. Solid State Chem., 2009, 182, 1009-1016.

14 D. Marrero-López, P. Núñez, M. Abril, V. Lavín, U. R. RodríguezMendoza and V. D. Rodríguez, J. Non-Cryst. Solids, 2004, 345-346, $377-381$.

15 G. Corbel, E. Chevereau, S. Kodjikian and P. Lacorre, Inorg. Chem., 2007, 46, 6395-404.

16 S. Basu, P. S. Devi and H. S. Maiti, J. Electrochem. Soc., 2005, 152, 2143-2147.

17 Z. S. Khadasheva, N. U. Venskovskii, M. G. Safronenko, A. V. Mosunov, E. D. Politova and S. Y. Stefanovich, Inorg. Mater, 2002, 38, 1168-1171.

18 G. Corbel, Y. Laligant, F. Goutenoire, E. Suard and P. Lacorre, Chem. Mater., 2005, 17, 4678-4684.

19 J. A. Collado, M. A. G. Aranda, A. Cabeza and S. Bruque, J. Solid State Chem., 2002, 85, 80-85.

20 P. Pinet, J. Fouletier and S. Georges, Mater. Res. Bull., 2007, 42, 935-942.

21 S. Georges, F. Goutenoire, Y. Laligant and P. Lacorre, J. Mater. Chem., 2003, 13, 2317.

22 D. Marrero-López, J. Canales-Vázquez, J. Ruiz-Morales, J. Irvine and P. Núñez, Electrochim. Acta, 2005, 50, 4385-4395.

23 F. Goutenoire, J. Solid State Chem., 1999, 142, 228-235.

24 X. C. Lu and J. H. Zhu, J. Electrochem. Soc., 2008, 155, B1053.

25 J. Jacquens, D. Farrusseng, S. Georges, J.-P. Viricelle, C. Gaudillère, G. Corbel and P. Lacorre, Fuel Cells, 2010, 10, 433-439.

26 M. Goel, E. Djurado and S. Georges, Solid State Ionics, 2011, 204-205, 97-103.

27 A. Caneiro, P. Bavdaz, J. Fouletier and J. P. Abriata, Rev. Sci. Instrum., 1982, 53, 1072.

28 Scribner Associates, ZView ${ }^{\mathrm{TM}}$, A Software Program for IES Measurements and Analysis, 2007.

29 J. Rodríguez-Carvajal, Physica B: Condensed Matter., 1993, 192, 55-69.

30 S. Georges, R. A. Rocha and E. Djurado, J. Phys. Chem. C, 2008, 112, 3194-3202.

31 I. R. Evans, J. A. K. Howard and J. S. O. Evans, Chem. Mater., 2005, 17, 4074-4077.

32 P. Lacorre, Solid State Sci., 2000, 2, 755-758. 